INFLAMMATORY BOWEL DISEASE

\title{
Incidence and prevalence of ulcerative colitis in Punjab, North India
}

\author{
A Sood, V Midha, N Sood, A S Bhatia, G Avasthi
}

See end of article for authors' affiliations

...........

Correspondence to: Dr A Sood, 6-E, Tagore Nagar, Opp. New DMC and $H$, Ludhiana- 141001 , Punjab, India; ajitsood@glide.net.in

Accepted for publication 8 July 2003
Introduction: Ulcerative colitis occurs worldwide. It is considered common in most of Europe and North America and uncommon in most of the developing Asian countries. The incidence/prevalence of ulcerative colitis varies not only according to geographical region but also with race and ethnicity. There are no reported data from India on the incidence of the disease and its prevalence.

Material and methods: A house to house survey was conducted by questionnaire, formulated to enquire about symptoms that are suggestive of ulcerative colitis. Those with prolonged diarrhoea with or without rectal bleeding were considered as suspected cases. These suspected cases were subjected to video sigmoidoscopy/colonoscopy and rectal biopsy. In addition, patients already diagnosed and receiving treatment for ulcerative colitis, encountered during the survey, were reviewed. Resurvey of the same areas was conducted after a one year interval to detect new cases. Using direct methods, standardised rates were calculated using world standard population weights $22,18,16,12,12,9,7,3$, and 1 for each 10 year age group. Standardised rates were also obtained separately for males, females, and combined populations, using the Punjab state 1991 population census data. Rates were also estimated according to UK 2000 population data. Ninety five per cent confidence intervals $(95 \% \mathrm{Cl})$ of prevalence and incidence rates of ulcerative colitis were estimated under the assumption that the distribution of cases followed a Poisson probability model.

Results: A total population of 51910 were screened from January to March 1999 . We identified 147 suspected cases and of these 23 were finally established as ulcerative colitis cases, giving a crude prevalence rate of 44.3 per 100000 inhabitants (95\% Cl 29.4-66.6). A second visit to the same areas after one year identified 10 suspected cases in a population of 49834 . Of these, three were confirmed as "definite" ulcerative colitis giving a crude incidence rate of 6.02 cases per 100000 inhabitants $(95 \% \mathrm{Cl}$ 1.2-17.6).

Conclusions: This is the first population based study from India reporting on the incidence and prevalence of ulcerative colitis. The disease frequency is not much less than that reported from Europe and North America.
U lcerative colitis is a chronic inflammatory bowel disease of unknown aetiology. It is a worldwide disorder with significant geographical heterogeneity, the highest prevalence rates having been reported from Northern and Western Europe and North America. ${ }^{1}$ A significant North-South gradient has also been observed in the prevalence of the disease, with rates being higher in Northern countries. ${ }^{23}$

Ulcerative colitis has been viewed from various studies in the past as being rare in developing countries of the world, including Asia. ${ }^{4}$ These obvious inconsistencies in disease distribution have been attributed possibly due to artefacts of methodology, genetic and environmental factors, or even subtler sociological variables such as stigma and underreporting. However, recent epidemiological experience is changing these premises. The disease is beginning to make itself known in populations where it had never been seen before, such as the Chinese in Hong Kong, the Chinese in Singapore, and the Arabs in Kuwait. ${ }^{5}$ An increased incidence is also being reported from the previously low incidence areas of Australia and Eastern Europe ${ }^{67}$ Moreover, the apparent gap in the incidence rates of inflammatory bowel disease between high and low incidence areas is narrowing. In a European prospective multicentre study, conducted between 1991 and 1993, the excess incidence in Northern countries was smaller than that previously suggested. ${ }^{8}$
Epidemiological data from Asia are scarce. More reliable information is available from Asian migrants in Western countries than from Asians in Asia. Only scant information is available from South Asia, including India. ${ }^{9-17}$ This therefore raises the need for descriptive population based epidemiological studies to reflect the true magnitude of the disease, which will define the public health burden of the disease. The aim of the present study was to establish the incidence and prevalence rates of ulcerative colitis in a population based study in the state of Punjab, India.

\section{METHODS}

\section{Population and area studied}

Punjab is a state in North India with an area of $50262 \mathrm{~km}^{2}$ with 17 districts, 120 towns, and 1242 villages. It is bound on the west by Pakistan, on the north by Jammu Kashmir, on the northeast by Himachal Pradesh, and on the south by Haryana and Rajasthan. It extends from the latitudes 29.3$32.30 \mathrm{~N}$ and longitude 73.5-76.5 E. Tributaries and subtributaries of the rivers Indus, Ravi, Sutlej, Beas, and Ghaggar flow across the state and provide a base for the most extensive canal system in India. The total population of the state is approximately 20.2 million people ( 1991 census) with about $63 \%$ Sikhs, 34\% Hindus, and 2\% minorities, which includes Christians and Muslims. The population is racially homogenous with a very low migratory rate. About one third 


\begin{tabular}{|llll|}
\hline \multicolumn{2}{|c|}{ Table 1} & \multicolumn{2}{c|}{ Demographics of the population surveyed } \\
\hline Age (y) & $\begin{array}{l}\text { Total population surveyed } \\
\text { (Punjab population) }\end{array}$ & $\begin{array}{l}\text { Males surveyed } \\
\text { (Punjab population) }\end{array}$ & $\begin{array}{l}\text { Females surveyed } \\
\text { (Punjab population) }\end{array}$ \\
\hline$<24$ & $14447(11063418)$ & $7572(9619716)$ & $6875(5181368)$ \\
$25-29$ & $6882(1674330)$ & $3756(876664)$ & $3126(797666)$ \\
$30-39$ & $11839(2676588)$ & $6216(1398$ 385) & $5623(1278203)$ \\
$40-49$ & $8344(1935325)$ & $4699(1035925)$ & $3642(899400)$ \\
$50-59$ & $4391(1243582)$ & $2460(659700)$ & $1931(583882)$ \\
$>60$ & $6007(1590059)$ & $3256(869683)$ & $2751(720376)$ \\
\hline
\end{tabular}

of the population lives in cities and towns while the rest live in villages.

\section{Survey method}

The survey was conducted between January and March 1999, and between January and March 2000. The survey team consisted of locally hired interviewers fluent in the dialect of the region and a team of doctors and paramedical staff from Dayanand Medical College and Hospital, Ludhiana, India. The aims and objectives of the study were fully explained to the survey team.

The districts identified for the survey were selected by a simple random technique. In the selected districts, 226 clusters were selected comprising streets, blocks, or mohallas as a sample unit, and from each cluster 50 houses were surveyed. Two thirds of the clusters were in rural and one third in urban areas. Residents of the area screened were informed a day earlier by the public communication system, mainly from a Gurudwara, Panchayat, or other religious place. The survey team visited every house of the cluster area selected for the survey. All available adult members of the household were interviewed and details noted according to the questionnaire. The rights of the subjects were safeguarded by maintaining the confidentiality of their data.

A medical history included history of diarrhoea with or without rectal bleeding. Those with prolonged diarrhoea ( $>4$ weeks) or those with rectal bleeding were interviewed again by a team of hospital team consultants (AS/VM). If the history was suggestive of colitis, they were considered as suspected cases and were transported to hospital for video sigmoidoscopy.

Stool examination was done on at least three occasions to rule out infection. The sigmoidoscopy procedure was performed after proctoclysis enema and rectal biopsy was done in all such cases. Full length colonoscopy was done later to determine disease extent in those cases that were confirmed to have ulcerative colitis. A repeat attempt was made to interview residents not available during the first visit. All residents were briefed about the proposed revisit after one year and were advised to report if symptoms suggestive of ulcerative colitis developed at any time in between. The same areas were visited again to detect those cases who had developed symptoms in the last year. Those who had developed symptoms suggestive of ulcerative colitis and reported to the hospital were also evaluated. The study was approved by the hospital ethics committee.

\section{Definitions}

A diagnosis of "definite" ulcerative colitis was made if a suspected case met the following criteria: (i) typical history of diarrhoea with or without blood and/or mucous in the stool; (ii) typical sigmoidoscopy picture with diffusely granular, friable, or ulcerated mucosa without rectal sparing or skip lesions; and (iii) histopathological findings suggestive of ulcerative colitis. Those subjects already diagnosed with ulcerative colitis were reviewed and only those with a suggestive history, and endoscopic and histological evidence supporting ulcerative colitis were accepted as cases.

A diagnosis of non-specific/infective colitis was made when there was a history of diarrhoea but insufficient endoscopic/ histological evidence to confirm a diagnosis of ulcerative colitis.

The extent of the disease, assessed by endoscope, was categorised as: (i) proctosigmoiditis-inflammation up to the sigmoid colon, (ii) left sided colitis-inflammation up to but not beyond the splenic flexure, and (iii) pancolitisinflammation beyond the splenic flexure. Disease severity was graded according to Baron's criteria. ${ }^{18}$

\section{Statistical analysis}

The entire population surveyed was considered at risk for ulcerative colitis. All residents with ulcerative colitis between January and March 1999 were included in the prevalence calculation. Incidence cases were defined as all new cases diagnosed in January-March 2000. Using a direct method, standardised rates were calculated using world standard population weights $22,18,16,12,12,9,7,3$, and 1 for each 10 year age group. Standardised rates were also obtained separately for males, females, and combined populations using the Punjab state 1991 population census figures. Rates were also standardised according to UK population 2000 data. Ninety five per cent confidence intervals (95\% CI) for prevalence and incidence rates of ulcerative colitis were estimated under the assumption that the distribution of cases followed a Poisson probability model.

\section{RESULTS}

The demographics of the study population are shown in table 1 . The survey sample comprised 51910 inhabitants and of these 147 suspected cases of ulcerative colitis were identified. From these 147 subjects, 128 agreed to undergo investigations and were transported to hospital for video sigmoidoscopy and histological evaluation. Eighty five subjects $(66.4 \%)$ had a normal mucosa (eight patients haemorrhoids, three microscopic colitis) and 27 (21\%) had mild oedema and/or patches of hyperaemia or tiny superficial ulcers suggestive of infective colitis. One patient had a growth on the rectum which on histology was found to be a carcinoma (table 2). A total of 23 subjects were established as having a "definite" diagnosis of ulcerative colitis and were considered as prevalence cases; 15 identified during

Table 2 Differential diagnosis of suspected prevalent cases of ulcerative colitis

\begin{tabular}{lc}
\hline Total suspected cases & 147 \\
Cases investigated & 128 \\
Normal & $85(66.4 \%)$ \\
Infective & $27(21.1 \%)$ \\
Carcinoma & $1(0.78 \%)$ \\
Ulcerative colitis & $15(11.7 \%)$
\end{tabular}




\begin{tabular}{|c|c|c|c|}
\hline Variable & $\begin{array}{l}\text { Newly diagnosed } \\
\text { cases }(n=15)\end{array}$ & $\begin{array}{l}\text { Previously diagnosed } \\
\text { cases }(n=8)\end{array}$ & $p$ Value \\
\hline Age (y) (mean (SD)) & $37.13(4.2)$ & $35.32(3.9)$ & $>0.19047$ \\
\hline $\operatorname{Sex}(M: F)$ & 7.8 & $3: 5$ & $>0.18493$ \\
\hline \multicolumn{4}{|l|}{ Diarrhoea duration (months) } \\
\hline \multicolumn{4}{|l|}{ No of stools per day (median } \\
\hline (range)) & $7(3-11)$ & $8(3-12)$ & $>0.15106$ \\
\hline Rectal bleeding & $11(73.3 \%)$ & $8(100 \%)$ & $>0.1094$ \\
\hline Pain & $15(100 \%)$ & $8(100 \%)$ & - \\
\hline Mucus & $15(100 \%)$ & $8(100 \%)$ & - \\
\hline Urgency & $15(100 \%)$ & $8(100 \%)$ & - \\
\hline Fever & 0 & $2(25 \%)$ & $<0.0487$ \\
\hline Past history & $2(13.3 \%)$ & $2(25 \%)$ & $>0.2076$ \\
\hline \multicolumn{4}{|l|}{ Grade } \\
\hline Mild & $2(13.3 \%)$ & 0 & $>0.1249$ \\
\hline Moderate & $10(66.7 \%)$ & $3(37.5 \%)$ & $>0.1081$ \\
\hline Severe & $3(20 \%)$ & $5(62.5 \%)$ & $>0.0432$ \\
\hline \multicolumn{4}{|l|}{ Extent } \\
\hline Pancolitis & $7(46.7 \%)$ & $3(37.5 \%)$ & $>0.1803$ \\
\hline Left sided & $6(40 \%)$ & $3(37.5 \%)$ & $>0.3268$ \\
\hline Proctosigmoiditis & $2(13.3 \%)$ & $2(25 \%)$ & $>0.2076$ \\
\hline
\end{tabular}

screening and eight through medical records, giving a crude prevalence rate of 44.3 per 100000 inhabitants (95\% CI 29.466.6).

Of these 23 patients, 10 were male $(43 \%)$, giving a crude prevalence of $53.6 / 10^{5}$ in males and $33.4 / 10^{5}$ in females $(\mathrm{p}=0.28)$. The age adjusted prevalence rate for males was $46.13 / 10^{5}$ inhabitants (95\% CI 22.43-69.8) and $27.16 / 10^{5}$ (95\% CI 6.0-48.3) for females, giving an overall age adjusted prevalence rate of $32.4 / 10^{5}$ (95\% CI 17.5-47.3) in the Punjab state. The age standardised prevalence rate as per the world population (1990) was $39.1 / 10^{5}$ inhabitants (95\% CI 22.14 $56.10)$ and as per the UK population (2000) $39.391 / 10^{5}(95 \%$ CI 22.838-55.945).

Median age at diagnosis was 36.5 years (range 18-52). Ten cases $(44 \%)$ had proctosigmoiditis, nine $(40 \%)$ had left sided disease, and four (16\%) had pancolitis on colonoscopy. Clinical features of newly and previously diagnosed cases were similar except for fever and endoscopically severe disease (table 3). Comparison between ulcerative colitis cases and the rest of the suspected cases revealed a longer duration of symptoms in suspected cases (table 4.)

On revisit, a population of 49834 were contacted, and 10 subjects who were identified as suspected cases were subjected to sigmoidoscopy. Three cases revealed endoscopic and histological findings suggestive of ulcerative colitis, giving a crude incidence rate of 6.02 cases per 100000 inhabitants (95\% CI 1.2-17.6).

\section{DISCUSSION}

This is the largest population based screening study for ulcerative colitis from India and we found an incidence of $6.02 / 10^{5}$ per year and a crude prevalence rate of $44.3 / 10^{5}$ inhabitants. The results of the only other population based study from our country is available in abstract form. ${ }^{9}$ Among Whites, the reported incidence of ulcerative colitis varies from 3 to $15 / 10^{5}$ persons per year with a prevalence of $50-80 / 10^{5} .{ }^{19}$ Our values are similar to published data from countries where ulcerative colitis is thought to be common, thus refuting the earlier belief that the disease is uncommon in India.

The incidence and prevalence rates observed in our study are the highest reported from the Asian subcontinent. Although epidemiological date are scarce from this part of the world for global comparison, reliable data for Asians in Asia are available from Japan and Korea. Incidence rates of ulcerative colitis from these countries are reported as 1.95/ $10^{5}$ /year and $1.23 / 10^{5} /$ year for Japan and Korea, respectively. The temporal trends of increasing incidence rates in these countries is believed to be real and related to the rapid westernisation of lifestyles, which includes dietary habits as well as environmental changes caused by industrialisation and urbanisation. ${ }^{11} 2021$ In India, verbally gathered information from clinicians also reveals an increasing incidence of the disease, which again is believed to be due to similar reasons. This information is however unsupported by

\begin{tabular}{|c|c|c|c|}
\hline Variable & Ulcerative colitis & Suspected cases & $p$ Value \\
\hline Age (y) (mean (SD) [range]) & $37.13(4.2)[18-52]$ & $39.01(4.8)[17-56]$ & $>0.13217$ \\
\hline $\operatorname{Sex}(M: F)$ & $7: 8$ & $51: 62$ & $>0.21716$ \\
\hline $\begin{array}{l}\text { History of diarrhoea (No of stools/day) } \\
\text { (median (range)) }\end{array}$ & $7(3-11)$ & $6(2-9)$ & $>0.16709$ \\
\hline Duration (months) (median (range)) & $8(3-12)$ & $14(3-18)$ & $<0.00963$ \\
\hline Bleeding & $11(73.3 \%)$ & $17(15 \%)$ & $<0.00086$ \\
\hline Abdominal pain & 15 (100\%) & 105 (92.9\%) & $>0.18531$ \\
\hline Mucus & 15 (100\%) & 108 (95.6\%) & $>0.13049$ \\
\hline Urgency & $15(100 \%)$ & $106(93.8 \%)$ & $>0.12593$ \\
\hline Fever & 0 & $6(5.3 \%)$ & $>0.13245$ \\
\hline Past history & $2(13.3 \%)$ & $21(18.6 \%)$ & $>0.26098$ \\
\hline
\end{tabular}


requisite concrete data. To study the temporal trends in India, data accumulation will take many more years. Studies from Japan and Korea report prevalence rates of 5.5-18.12/10 cases and $7.57 / 10^{5}$, respectively which, following similar increasing incidence trends, are likely to reach $58.5 / 10^{5}$ and $36.9 / 10^{5}$ persons, respectively. A prevalence study from Singapore showed three times higher disease prevalence rates among Indians compared with the Chinese population. ${ }^{22}$ Another study in a migrant South Asian population in the UK revealed a significantly higher prevalence in Hindus and Sikhs than in Europeans. ${ }^{23}$

The reasons for delayed epidemiological data from our country are many: lack of a system for proper record keeping on ulcerative colitis, popular alternative therapies, limited access to health care and diagnostic facilities, and lack of physician awareness. For the majority of chronic illnesses in India, epidemiological inferences are drawn from hospital data and directly extrapolated to the general population. A few epidemiological studies of ulcerative colitis based on hospital statistics are available from our country, which may be an underestimate of the total disease quantum as the majority of patients are never hospitalised. ${ }^{24} 25$

As true prevalence data provide a snapshot of the burden of the disease in society, we endeavoured to carry out this house to house survey to determine the prevalence more precisely. Apart from the practical problems of manpower and resources, we also encountered difficulties in transporting suspected cases to hospital. This may have resulted in slight underreporting of the prevalence rate as 19 suspected cases could not be evaluated by sigmoidoscopy. We also possibly missed those cases of ulcerative colitis who remained in remission after their first attack.

However, the strengths of our study include: the study design was based on a population survey, very low migratory rates in the population studied, and the "definite" diagnosis of ulcerative colitis made after endoscopy and histopathology. Previously diagnosed cases were included only if they had hospital based records of colonoscopy and biopsy. Studies have reported asymptomatic ulcerative colitis identified on the basis of screening for faecal occult blood. They found that such cases have milder symptoms and more frequent right sided disease. ${ }^{26} 27$ In our field survey, we identified 15 previously undetected cases of ulcerative colitis. These cases were not truly asymptomatic but probably remained undiagnosed due to lack of proper investigative work up. Moreover, the aim of our study was different as we tried to detect symptomatic cases. The newly diagnosed cases differed in comparison with cases observed in hospital practice as patients diagnosed in hospital had higher incidences of fever and more severe disease. Rectal bleeding was significantly more common in cases diagnosed as ulcerative colitis compared with suspected cases who did not have ulcerative colitis; in contrast suspected cases had a longer duration of symptoms which was possibly attributable to irritable bowel syndrome.

In conclusion, this is the first study that has provided evidence of the dynamic epidemiology of ulcerative colitis in India. In the Western world, a rapid increase in the frequency of inflammatory bowel disease occurred between 1965 and 1980, followed by a slower increase, reaching a plateau, and then subsequently declining in some areas. Whether the seemingly rising prevalence in India will follow the same pattern remains to be seen.

\section{Authors' affiliations}

A Sood, V Midha, G Avasthi, Department of Medicine, Dayanand Medical College and Hospital, Punjab, India

N Sood, Department of Pathology, Dayanand Medical College and Hospital, Punjab, India

A S Bhatia, Department of Community Medicine, Christian Medical College and Hospital, Ludhiana, Punjab, India

\section{REFERENCES}

1 Whelan G. Epidemiology of inflammatory bowel disease. Med Clin North Am 1990:74:1-12.

2 Farrokhyar F, Swarbrick ET, Irvine EJ. A critical review of epidemiology studies in inflammatory bowel disease. Scand J Gastroenterol $2001 ; 36: 2-15$.

3 Loftus EV, Schoenfeld P, Sandborn WJ. The epidemiology and natural history of Crohn's disease in population based patient cohort from $\mathrm{N}$ America: a systematic review. Aliment Pharmacol Ther 2002;16:51-60.

4 Yang SK, Edward Loftus Jr, Sandborn William J. Epidemiology of Inflammatory bowel disease in Asia. Inflamm Bowel Dis 2001;7:260-70.

5 Hossain J, Al-Faleh FZ, Al-Mofleh I, et al. Does ulcerative colitis exist in Saudi Arabia? Analysis of thirty-seven cases. Saudi Med J 1989;10:360-2.

6 Jovanovic Z. Epidemiology of Crohn's disease in Rijeka-Istra region (in Serbo-Croation). Lije Viesn 1999;121:8-13.

7 Anseline PF. Crohn's disease in the Hunter Valley region of Australia. Aust NZ J Surg 1995;65:564-9.

8 Shivananda S, Lennard Jones J, Logan R, et al. Incidence of inflammatory bowel disease across Europe: is there a difference between north and south? Result of the European Collaborative Study on Inflammatory Bowel Disease (EC-IBD). Gut 1996;39:690-7.

9 Khosla SN. Ulcerative colitis in India. World Congress of Gastroenterology, Sydney, 1990. Abingdon: The Medicine Group, 1990:576.

10 Morita N, Toki S, Hiroshashi T, et al. Incidence and prevalence of inflammatory disease in Japan: nationwide epidemiology survey during the year: 1991. J Gastroenterol 1995;30(suppl 8):1-4.

11 Yoshida Y, Murata Y. Inflammatory bowel disease in Japan: studies of epidemiology and etiopathogenesis. Med Clin North Am 1990;74:67-90.

12 Yang SK, Hong WS, Min Yl, et al. Incidence and prevalence of ulcerative coltis in the Songpa Kangdong district, Seoul Korea 1986-1997. J Gastroenterol Hepatol 2000;15:1037-42.

13 Lai CL, Wu PC, Wong KL, et al. Clinical features of ulcerative proctocolitis in Hong Kong Chinese: a review of three decades. Am J Proctol Gastroenterol Colon Rectal Surg 1985;1:14-19.

14 Fung WP, Monteiro EH, Murugasu JJ, et al. Non-specific ulcerative colitis in Chinese and Indians in Singapore. Med J Aust 1971;2:361-5.

15 Lee SK. Crohn's disesae in Singapore. Med J Aust 1974;1:266-9.

16 Al-Nakib B, Radhakrishnan S, Jacob GS, et al. Inflammatory bowel disease in Kuwait. Am J Gastroenterol 1984;79:191-4.

17 Radhakrishanan S, Zubaidi G, Daniet Metrogel, et al. Ulcerative colitis in Oman. A prospective study of the incidence and disesae pattern form 1987 to 1994. Digestion 1997:58:266-70.

18 Baron JH, Connell AM, Lennard Jones JE. Variation between observers in describing mucosal appearances in proctocolitis. Br Med J 1964;1:89.

19 Mendeloff Al, Calkins BM. The epidemiology of idiopathic inflammatory bowel disease, 4th ed. Philadelphia: Lea and Febiger, 1995:31-68.

20 The Epidemiology Group of the Research Committee of IBD in Japan. A case control study of ulcerative colitis in relation to dietary and other factors in Japan. J Gastroenterol 1995;30(suppl 8):9-12.

21 Shoda R, Matsueda K, Yamato S, et al. Epidemiologic analysis of Crohn's disease in Japan: increased dietary intake of $n-6$ polyusaturated fatty acids and animal protein relates to the increased incidence of Crohn's disesae in Japan. Am J Clin Nutr 1996;63:741-5.

22 Tan CC, Kang JY, Guan R, et al. Inflammatory bowel disease: an uncommon problem in Singapore. J Gastroenterol Hepatol 1992;7:36-2.

23 Probert CS, Jayanthi V, Huges AO, et al. Prevalence and family risk of ulcerative colitis and Crohn's disease: an epidemiological study among Europeans and South Asians in Leicestershire. Gut 1993;34:1547-51.

24 Chuttani HK, Nigam SP, Sama SK, et al. Ulcerative colitis in the tropics. $\mathrm{Br}$ Med J 1967;4:204-7

25 Tandon BM, Mathur AK, Mohapatra LN, et al. A study of the prevalence and clinical pattern of non-specific ulcerative colitis in Northern India. Gut 1965:6:448-53.

26 Howarth GF, Robinson MH, Jenkins D, et al. High prevalence of undetected ulcerative colitis: data form the Nottingham fecal occult blood screening trial. Am J Gasteroenterol 2002;97:690-4.

27 Sakata S, Niwa Y, Goto H, et al. Asymptomatic inflammatory bowel disease with special reference to ulcerative colitis in apparently healthy persons. Am J Gastroenterol 2001;96:735-9. 